\title{
How We (Sometimes Do Not) Evaluate Design Support: A Review of How Design Support Is Evaluated in Practice
}

\author{
Camilla Arndt Hansen ${ }^{1}$, Ali Gürcan Özkil ${ }^{2}$ \\ ${ }^{1}$ Technical University of Denmark, \\ Department of Mechanical Engineering \\ cahan@mek.dtu.dk \\ ${ }^{2} G N$ Audio $A / S$ \\ aliozkil@gmail.com
}

\begin{abstract}
Design support holds the potential to improve the performance of new product development. However, this potential is not fulfilled, as design support does not have the expected impact in industry, where practitioners are unaware of its existence or simply do not adopt it. Rigorous evaluation of design support is needed to increase uptake in industry, as it enables adjustments and improvements based on feedback from users.

Through a meta-research study of the conference proceeding from the international design conference NordDesign, this paper provides insights on the current evaluation practices in a section of the design research community. All 98 papers from the most recent conference in 2018 were reviewed to identify how much of the presented research focussed on design support and how this was evaluated. We coded for parameters such as type of design support introduced, evaluation method, evaluation objective, and inclusion of qualitative measures. Additionally, the relative impacts of design support papers were compared.

The results shows that there was a skewed balance between research on design support, and especially research that presented new design support, compared to research on design theory or design practices. 65\% of papers at NordDesign 2018 focussed on design support, and 64\% of the design support papers introduced new design support while 39\% evaluated existing support. However, the papers about new design support also made less effort to evaluate the support and showed less rigour in their evaluations. 56\% of the new support was not evaluated in the papers at all and $78 \%$ of new support was not evaluated with its intended users.

The results imply that there is still a need to improve evaluation practices during the development of design support. Further balance is needed between research that understands design and research that supports it. Developed design support should to a larger extend be evaluated and adjusted after its instroduction in a paper and more focus should be given to the users of design support - the designers.
\end{abstract}

Keywords: Design support, Design methods, Evaluation, Design research, Meta-research 


\section{Introduction}

Since Donald Norman named himself 'User Experience Architect' at Apple in 1993, more and more companies have employed people specifically dedicated to understanding their users (Nielsen, 2017). "Empathise with your user!" say user centred designers, design thinkers, and user experience designers, "Otherwise you do not know if your solution will fulfil its users' needs" (Kouprie, 2009). However, do we as design researchers remember our users, when we develop methods to support designers during new product development in industry?

The purpose of design research has been described as both understanding and supporting design (Blessing \& Chakrabarti, 2009). It includes both the development of models that describe and explain design, as well as the use of existing theory to produce support that can improve design practices. It is a popular view among design researchers that companies need support to develop successful products in today's complex, fast-paced and highly competitive markets (Jagtap et al., 2014). Use of design support has also been shown to improve the performance of new product development in companies, for instance by increasing quality or reducing failure costs (Booker, 2012; Yeh et al., 2010). Therefore, much design support is being developed to assist practitioners, but in spite of its potential, the utilisation of design support in industry is lower than expected and practitioners often do not know about the existence of relevant support (Blessing \& Chakrabarti, 2009; Jagtap et al., 2014; Jensen, 2018; López-Mesa \& Bylund, 2011; Yeh et al., 2010). If practitioners are unaware or unwilling to apply the design support created through design research, we cannot claim to fulfil the purpose of supporting design in practice.

Several factors have been identified to explain the low impact of design support in industry; for instance that the study of engineering processes is done in isolation from engineers (LópezMesa \& Bylund, 2011). Engineering design researchers lack understanding of the industrial processes that they attempt to assist, which has caused implementation issues to be overlooked and lead to insufficient focus on the needs of companies (Blessing \& Chakrabarti, 2009; LópezMesa \& Bylund, 2011). This was evident in the research disseminated at the international design conference ICED in 97 and 99, where only 37.5\% of the papers that developed new tools and methods dealt with issues related to the implementation of the new design support in industry (Cantamessa, 2001). To increase the likelihood of design support being successfully adopted in industry, it must be sufficiently evaluated (Jagtap et al., 2014). Evaluation ensures that the desired effect is achieved, checks that the assumptions made during the development of the support holds true, and uncovers unexpected side effects (Blessing \& Chakrabarti, 2009). It allows researchers to modify the support based on feedback from its intended users.

Much of the existing literature on this topic is based on studies in industry and has not investigated the actual practices of researchers. This paper offers detailed insights on how design support was evaluated at a recent design conference. It provides an updated view on evaluation practices and identifies areas that still need further improvement and guidance.

\subsection{Research Questions}

This study contributes to the overall question: How is design support evaluated in practice? The question is answered by investigating the evaluation of design support at the design conference NordDesign, through a review of all the papers presented at the most recent conference in 2018. This leads us to the following research questions:

1. How much of the research presented at NordDesign 2018 concerned design support?

2. How was design support evaluated at NordDesign 2018?

3. What is the impact of design support presented at NordDesign 2018? 


\subsection{Definitions}

In this paper, we use the definition of design support from Blessing and Charkrabarti (2009), who refer to 'support' as "the possible means, aids, and measures that can be used to improve design", providing examples such as methodologies, procedures, methods, techniques, and software tools. Thus, support can assist designers, engineers, developers, or other types of employees in the development of products, services, or other solutions. When we investigate the evaluation of design support in this paper, we use the term 'evaluation' broadly to mean any type of assessment, validation, application, or review of the support in focus.

\section{Methods}

Through meta-research, the conference proceedings from the most recent NordDesign conference were reviewed to investigate how much of the presented research involved design support and how this was evaluated. Meta-research is a relatively new practice that is used to study research and the practices within research in order to "understand and improve how we perform, communicate, verify, and reward research" (Ioannidis, 2018). As we investigate evaluation practices in the full proceedings from a conference covering many different topics within design research, the results illustrate the practices within a section of the design research community.

The 98 papers from NordDesign 2018 were coded in three rounds, as illustrated in Figure 1. In the first coding round, all papers were reviewed to identify studies concerning design support. In the second coding round, it was identified whether the design support papers were evaluating existing design support or introducing new support. In the third round, the design support papers were coded for a number of specific parameters related to the evaluation of design support, see Table 1. We also recorded the number of citations for each paper from Scopus to quantify the impact of design support papers. Finally, results were analysed and compared to answer the research questions.

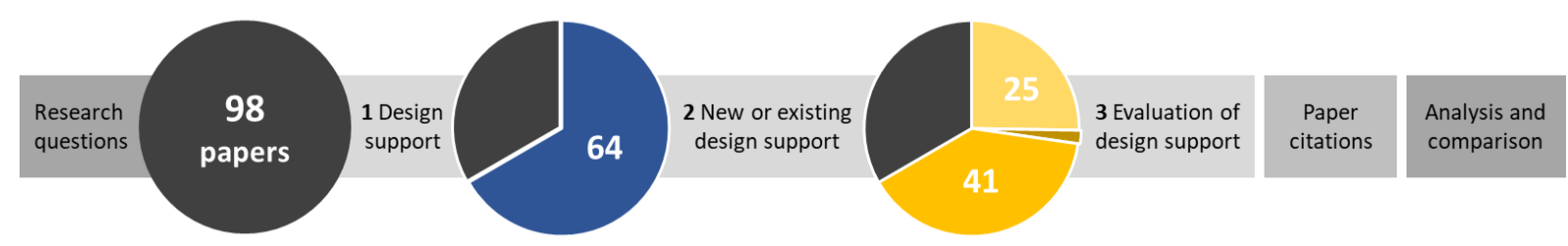

Figure 1. Coding of papers from NordDesign 2018

\subsection{Proceedings of NordDesign 2018}

NordDesign is a bi-annual Nordic design conference that presents research is the area of engineering and product design within topics such as manufacturing, ergonomics, and sustainability (Norddesign 2018, n.d.). NordDesign 2018 was the $13^{\text {th }}$ and most recent conference and took place at Linköping University in Sweden.

Ninety-eight papers were published in the conference proceedings for NordDesign 2018 (The Design Society, 2018). During the conference days, 14-17 August, the papers were presented in 24 sessions grouped by topics such as machine learning, prototyping, design process, and virtual and augmented reality. Contributions came from 10 different countries; $34 \%$ from Sweden, 30\% from Germany, 9\% from Norway, 7\% from UK, 5\% from Finland, 4\% from USA, $3 \%$ from Brazil, $3 \%$ from Italy, $2 \%$ from Denmark, and 2\% from the Netherlands. 


\subsection{Coding}

For the review of conferences proceedings, we selected a number of specific parameters to describe design support and its evaluation. To investigate the amount of the presented research that concerned design support, we identified 1) the total number of papers about design support, 2 ) the number of papers concerning existing support vs. papers that introduced new support, and 3) that types of support that were introduced. Many different parameters can be used to describe how design support is evaluated. In this paper, we focus on the following: 1) whether the design support papers evaluated the design support in focus, 2) whether they described a need for future evaluations, 3) which methods were used for evaluations, 4) who carried out the evaluation, 5) the evaluation objectives, 6) whether they included quantitative measures in the evaluations, 7) whether they compared the design support in focus to other support, and 8) whether the evaluated design support was introduced by themselves or other authors.

Table 1 shows the coding manuscript used to review the NordDesign 2018 papers. To identify papers on design support, we read the abstracts of all 98 papers and identified whether the introduction, application, evaluation or review of design support was a main objective in the paper. If this was not clear from the abstract alone, the conclusion was read as well. Applying the broad definition of 'design support' from the Introduction, the papers can describe many types of support such as methods, frameworks, guidelines, or software tools. To be categorised as design support research, the paper must focus on specific design support or a specific group of design support. Examples of papers that did not concern design support are papers that investigated design practices in industry or papers on end user behaviour.

Table 1. Coding manuscript. Only design support papers were coded in round 2 and 3

\begin{tabular}{|l|l|l|}
\hline Round 1 & Design support & Yes, No \\
\hline \multirow{5}{*}{ Round 2 } & Existing or new support & $\begin{array}{l}\text { Existing support, New support, } \\
\text { Both existing and new support }\end{array}$ \\
\hline \multirow{5}{*}{ Round 3 } & Introduced support type (new support) & $\begin{array}{l}\text { [Descriptions used in abstract and } \\
\text { conclusion] }\end{array}$ \\
\cline { 2 - 3 } & Type of evaluation & Internal, external, no evaluation \\
\cline { 2 - 3 } & Stated need for future work (new support) & Yes, No \\
\cline { 2 - 3 } & Stated need for evaluation by intended users (new support) & Yes, No \\
\cline { 2 - 3 } & Evaluation method & [Categorisation] \\
\cline { 2 - 3 } & Evaluation objective & [Categorisation] \\
\cline { 2 - 3 } & Use of quantitative measures in evaluation & [Categorisation] \\
\cline { 2 - 3 } & Compared design support & Yes, No \\
\cline { 2 - 3 } & Evaluation of support by author (existing support) & Yes, No \\
\cline { 2 - 3 } & Compares with existing methods & Yes, No \\
\hline
\end{tabular}

After the first coding round, 64 papers were identified as design support papers. These were further coded in round 2 and 3. In the second round of coding, we investigated whether the papers evaluated already existing designs support and/or whether new design support was presented in the papers. After the initial categorisation, the final coding round was a deeper investigation of the evaluation practices in the 64 NordDesign papers about design support. To review the evaluation process according to Table 1, we read the abstracts, conclusions and, if needed, any additional relevant parts of the paper. There were no predefined sub-codes for 'Evaluation method', 'Evaluator', or 'Evaluation objective'. After identifying descriptions of these from all papers, they were grouped into categories. 


\section{Results}

In the following, we present results from our investigation of design support research at NordDesign 2018. First, we show the amount of research about design support disseminated at the conference, then how design support was evaluated in the papers, and finally we compare the impact of the papers.

\subsection{RQ1: Amount of Design Support Research}

Table 2 presents a summary of the results concerning the amount and type of design support presented at NordDesign 2018. The results are presented in further detail below.

Table 2. Summary of results concerning the amount of design support research

\begin{tabular}{|l|c|c|c|}
\hline Paper parameter & \# of papers & $\begin{array}{c}\text { \% of support } \\
\text { papers }\end{array}$ & $\begin{array}{c}\text { \% of total } \\
\text { papers }\end{array}$ \\
\hline Design support papers & 64 & $100 \%$ & $65.3 \%$ \\
\hline Existing design support & 25 & $39.0 \%$ & $25.5 \%$ \\
\hline New design support & 41 & $64.0 \%$ & $41.8 \%$ \\
\hline New 'approach' & 20 & $31.3 \%$ & $20.4 \%$ \\
New 'framework' & 9 & $14.1 \%$ & $9.2 \%$ \\
New 'methodology'; 'method' & 7 & $10.9 \%$ & $7.1 \%$ \\
New 'tool' & 4 & $7.8 \%$ & $5.1 \%$ \\
New 'guidelines'; 'model' & 2 & $6.3 \%$ & $4.1 \%$ \\
New 'process'; 'strategy' & & $3.1 \%$ & $2.0 \%$ \\
New 'matrix'; 'environment'; 'procedure'; 'course'; & & & \\
'arena'; 'roadmap'; 'teaching method'; 'workshop'; & 1 & $1.6 \%$ & $1.0 \%$ \\
\hline
\end{tabular}

\subsubsection{5\% of Papers Focused on Design Support}

A majority of research presented at NordDesign 2018 had a major focus on design support. Either they reviewed, applied, or evaluated existing design support or they introduced newly developed support. As a broad definition of 'design support' was applied, the papers cover a wide variety of support such as business games, use of Virtual Reality for concept evaluation, courses for engineering students, or new approaches for design optimization.

About one third of papers did not focus on design support. These can be divided as such: $18 \%$ focused on end users or products, $9 \%$ described designer behaviour and practices in industry without focussing on any particular design support, and 7\% dealt with design research. These papers contain knowledge that may be relevant to the designer, but did not present it in a format intended to support the design process.

\subsubsection{9\% of Design Support Papers Evaluated Existing Design Support, While 64\% Introduced New Design Support}

Figure 2 looks closer at the 64 papers about design support. Twenty-five papers focused on existing design support i.e. support that has been introduced in previous research, while 41 papers introduced new design support. Only two papers included both existing and new design support. There was a high focus on introducing new design support at NordDesign 2018, as $42 \%$ of all conference papers that year introduced new support. 

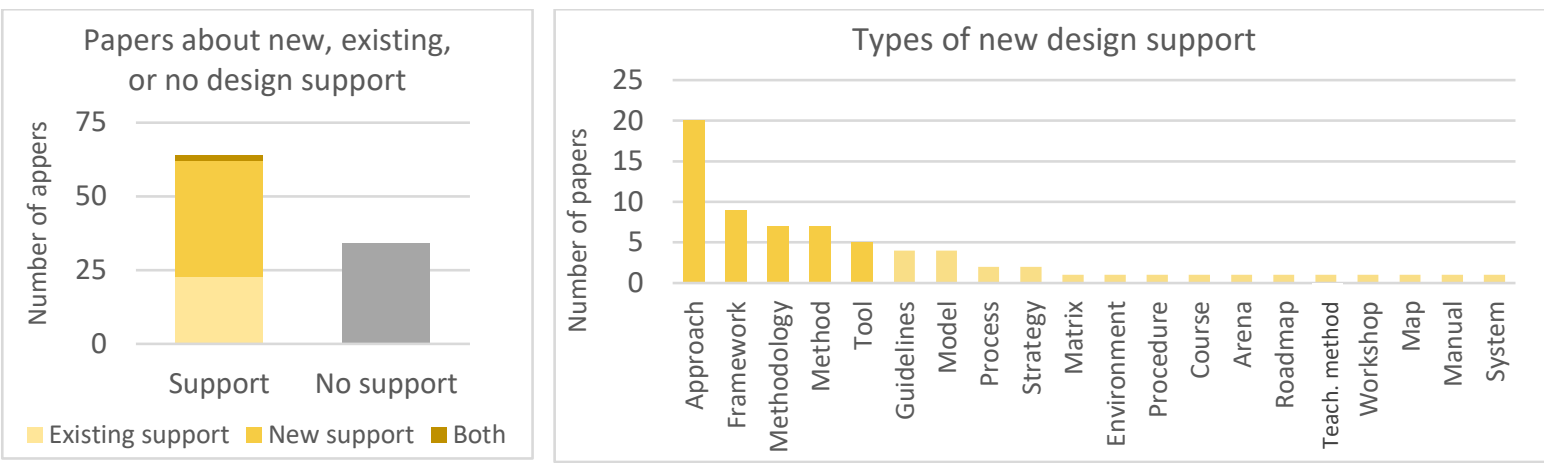

Figure 2. The amount of papers that evaluated existing design support compared to papers that introduced new support (left) and the different types of design support that were introduced in the 41 papers (right). All terms used in the paper abstract and conclusion are included in the graph.

\subsubsection{Twenty Different Terms Were Used to Describe New Support in 41 Papers}

New design support was introduced in 41 papers. Figure 2 shows that a large variety of design support was introduced, here showing the authors' own descriptions in the paper abstracts and conclusions. Twenty-five of the papers used more than one description or introduced more than one type of support. For instance, one paper presented a "first approach for an agile development process" in the abstract, while the conclusion described that "In this paper, a methodology was presented". The most commonly used description was 'approach', which was used in a little more than half of all the papers that introduced new support. The terms 'framework', 'methodology', 'method', and 'tool' were used 5-9 times each, while 11 types of support descriptions such as 'teaching method' or 'manual' were only used in a single paper.

\subsection{RQ2: Evaluation of Design Support}

Below, we present how design support was evaluated in the 64 papers at NordDesign 2018 that either evaluated existing design support or presented new support, see summary Table 3.

Table 3. Summary of results concerning the evaluation of design support

\begin{tabular}{|l|l|l|l|}
\hline Paper parameter & Existing support & New support & All support \\
\hline Evaluation of design support & $24(96.0 \%)$ & $18(43.9 \%)$ & $41(64.1 \%)$ \\
- Internal evaluation & $10(40.0 \%)$ & $9(22.0 \%)$ & $19(29.7 \%)$ \\
- External evaluation & $14(56.0 \%$ & $9(22.0 \%)$ & $23(35.9 \%)$ \\
\hline Need for future work & - & $33(80.5 \%)$ & $33(51.6 \%)$ \\
Need for future external evaluation & - & $13(31.7 \%)$ & $13(20.3 \%)$ \\
\hline Evaluation through: & & & \\
Theoretical case study & $5(20.0 \%)$ & $7(17.1 \%)$ & $12(18.8 \%)$ \\
Industry case study & $3(12.0 \%)$ & $6(14.6 \%)$ & $9(14.1 \%)$ \\
Interview or questionnaire & $5(20.0 \%)$ & $3(7.3 \%)$ & $8(12.5 \%)$ \\
Literature review & $6(24.0 \%)$ & $0(0 \%)$ & $6(9.4 \%)$ \\
Application at university & $4(16.0 \%)$ & $2(4.9 \%)$ & $6(9.4 \%)$ \\
Experiment & $4(16.0 \%)$ & $0(0 \%)$ & $4(6.3 \%)$ \\
Other & $0(0 \%)$ & $1(2.4 \%)$ & $1(1.6 \%)$ \\
\hline Objective: & $6(24.0 \%)$ & $0(0 \%)$ & $6(9.4 \%)$ \\
Gaps in existing methods & $7(28.0 \%)$ & $6(14.6 \%)$ & $13(20.3 \%)$ \\
General learnings & $10(40.0 \%)$ & $3(7.3 \%)$ & $13(20.3 \%)$ \\
Performance or effect & $0(0 \%)$ & $3(7.3 \%)$ & $3(4.7 \%)$ \\
Validation or verification & $1(4.0 \%)$ & $6(14.6 \%)$ & $7(10.9 \%)$ \\
Application & & $9(22.0 \%)$ & $19(29.7 \%)$ \\
\hline Evaluated by: & $10(40.0 \%)$ & $7(17.1 \%)$ & $15(23.4 \%)$ \\
Authors & $8(32.0 \%)$ & & \\
Professionals & & & \\
\hline
\end{tabular}




\begin{tabular}{|l|l|l|l|}
\hline Students & $9(36.0 \%)$ & $2(4.9 \%)$ & $11(17.2 \%)$ \\
Teachers & $1(4.0 \%)$ & $0(0 \%)$ & $1(1.6 \%)$ \\
(Not stated) & $1(4.0 \%)$ & $0(0 \%)$ & $1(1.6 \%)$ \\
\hline Compared design support & $12(48.0 \%)$ & $1(2.4 \%)$ & $13(20.3 \%)$ \\
Did not compare support & $12(48.0 \%)$ & $16(39.0 \%)$ & $28(43.8 \%)$ \\
\hline Used qualitative measures & $12(48.0 \%)$ & $5(12.2 \%)$ & $17(26.6 \%)$ \\
Did not use qualitative measures & $12(48.0 \%)$ & $13(31.7 \%)$ & $25(39.1 \%)$ \\
\hline Support by same author & $7(28.0 \%)$ & - & $7(10.9 \%)$ \\
Support by different author & $17(68.0 \%)$ & - & $17(26.6 \%)$ \\
\hline
\end{tabular}

\subsubsection{Support was Evaluated in 64\% of All Design Support Papers, but 56\% of New Support} was Not Evaluated and 78\% of New Support Was Not Evaluated by Intended Users

Figure 3 shows the overall evaluation in the 64 support papers. A noticeable difference can be found between the evaluation of new and existing support. All papers on existing support, apart from one, performed an evaluation of the support in focus. In contrast, more than half the papers on new support introduced the support without any kind of evaluation.

\subsubsection{1\% of Papers That Introduced New Support Described Future Work, but only 32\% Described the Need for Future Evaluation by External Users}

New design support was introduced in 41 papers. Figure 3 shows that 33 of these expressed a need for future development of the support, such as expanding it or improving its quality. However, only 13 papers described the need for evaluation by its target users.
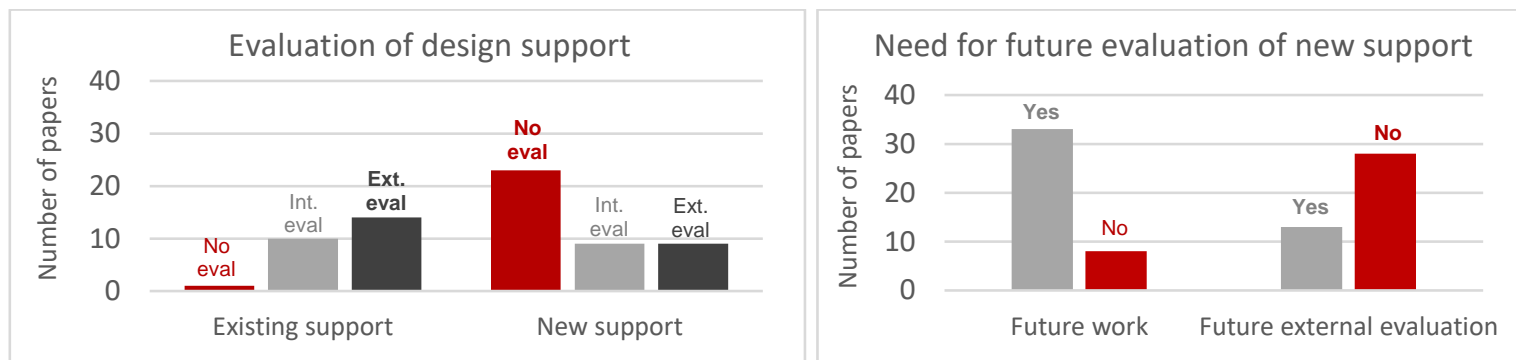

Figure 3. The extent to which design support was evaluated (left) and the number of papers that mention a need for future work and a need for future evaluation with intended users (right)

\subsubsection{Theoretical or Industry Case Studies Were Applied in 51\% of Evaluations}

The 41 papers that evaluated support applied the different methods for evaluation shown in Figure 4. The results show that we have employed a broad definition of 'evaluation' as everything from literature reviews and theoretical case studies carried out by the authors are included. Theoretical case studies and case studies with industry were the most common methods for evaluation. Literature reviews and experiments were only used for existing support.

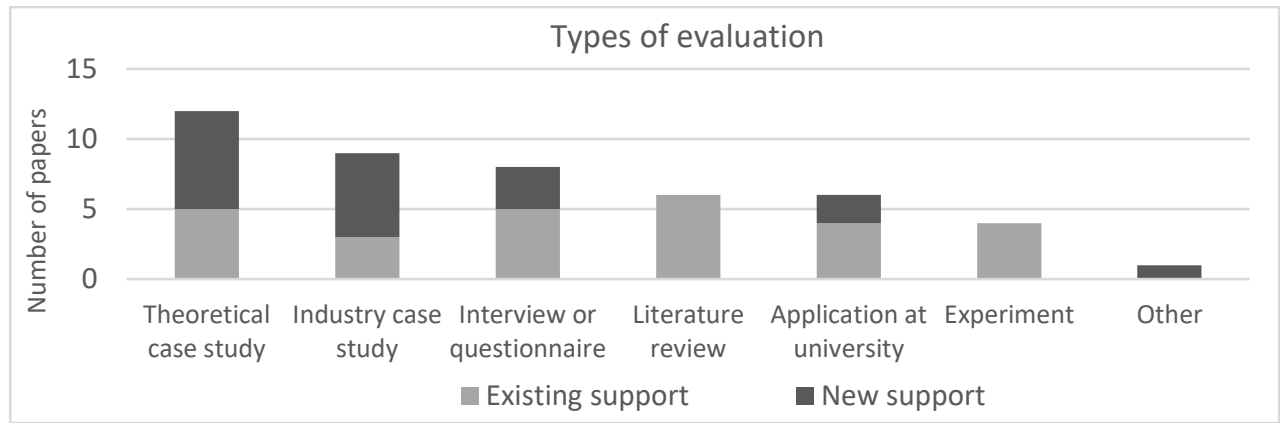

Figure 4. The overall methods used for evaluating in 41 design support papers. 


\subsubsection{0\% of Evaluations Only Involved the Authors Themselves}

Figure 5 shows that almost all evaluations were carried out by three groups of people; the authors, professionals from industry, or students. Some papers included more than one group in the evaluations. Of the 41 papers that evaluated design support, $60 \%$ evaluated with external users, while the authors alone carried out the evaluations in the remaining papers.

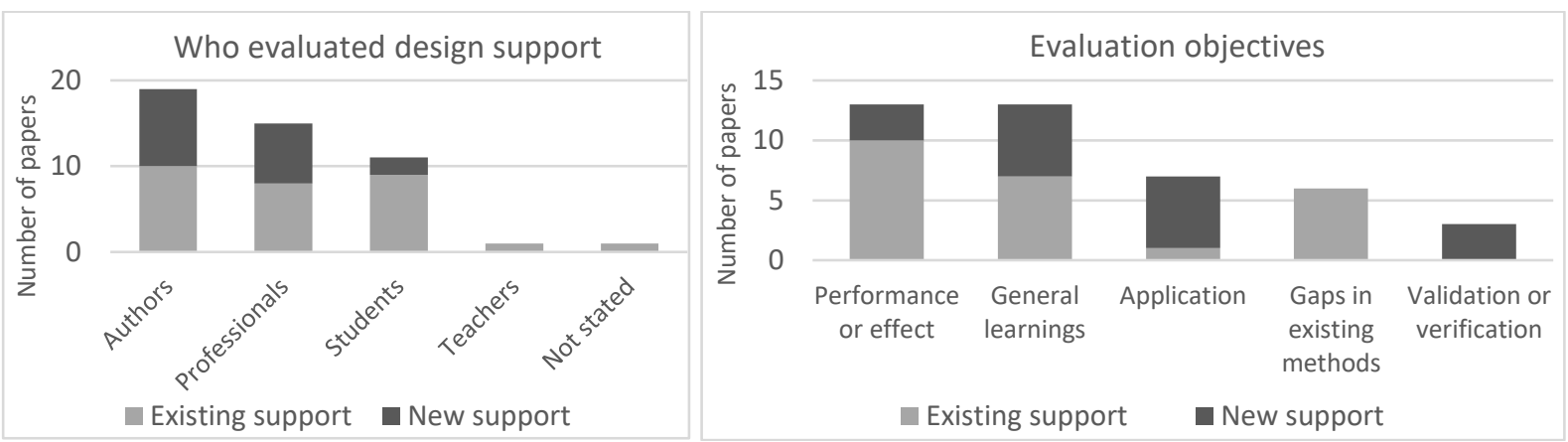

Figure 5. Types of evaluation objectives (left) and those who evaluated the design support (right)

\subsubsection{Assessing Performance and Exploring General Learnings Were the Most Common Objectives for Evaluations}

A clear difference between evaluation objectives for existing and new support can be seen in Figure 5. The most common objective for existing support was to evaluate the performance or effect of applying the support, including the perceived effect by users. In contrast, the most common objectives for new support was simply to confirm that it could solve a stated problem or to identify general learnings from using the support, such as its benefits or limitations. Thus, the evaluation objectives for new support were often more explorative and less clearly defined. Although these were counted as evaluations, many of the papers did not present a clear focus for the evaluations and/or did not conclude on results. These papers simply demonstrated that it was theoretically possible to apply the support.

\subsubsection{Papers on Existing Support Used Quantitative Measures More Often and Made More Comparisons between Design Support than Papers That Evaluated New Support Did}

Half of the papers that evaluated existing support made comparisons to other design support and half of the papers included quantitative measures in the evaluation. Figure 6 shows that only one paper that introduced new support compared this to other support and only $28 \%$ of evaluations of new support included quantitative measures.

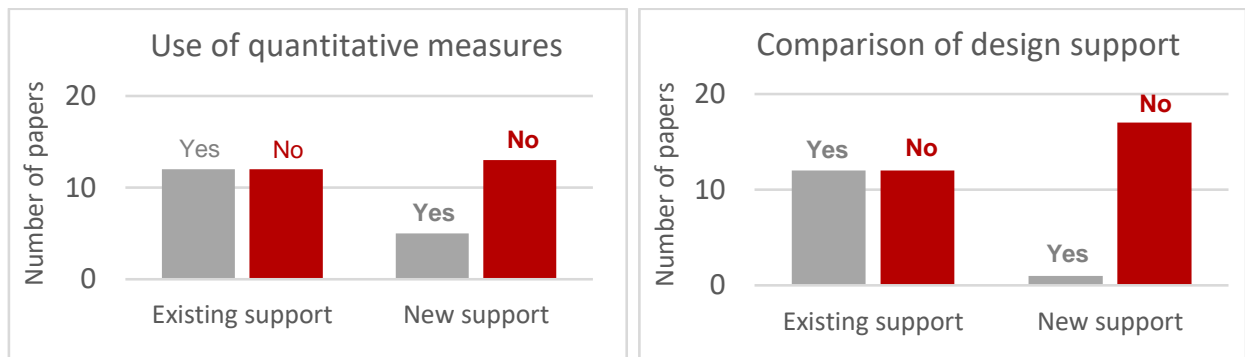

Figure 6. Use of quantitative measures in the evaluation (left) and comparisons of design support (right)

\subsubsection{8\% of Papers about Existing Design Support Evaluated Support by a Different Author}

In 17 of the 25 papers about existing design support, a different author had originally introduced the support. The rest evaluated support that had previously been introduced by one of the authors themselves. 


\subsection{RQ3: Impact of Design Support Papers}

The number of times the conference papers have been cited since 2018 can be seen in Figure 7 . $75 \%$ of papers have not been cited, and $89 \%$ have not been cited by other authors. The highest number of total citations is 4 , which one paper has received.

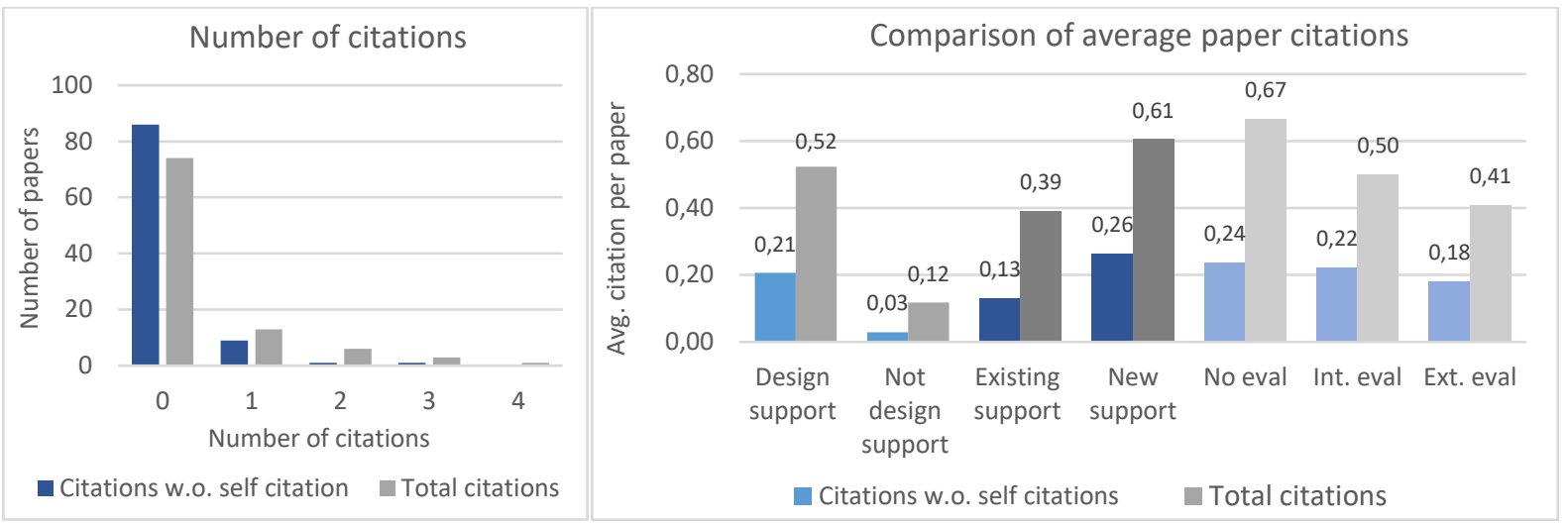

Figure 7. Number of paper citations (left) and a comparison of average paper citations for different groupings of papers (right). Both total citations and citations without self-citations are shown

The average citation per paper is 0.38 , but 0.14 if self-citations are excluded. Figure 7 shows a comparison of the average citations of papers. Papers concerning design support were cited seven times more often than the group of papers that did not concern design support. Furthermore, papers that introduce new support were cited more often than papers focussing on existing support. If we compare different degrees of evaluation, the papers that did not evaluate design support were cited more frequently than papers that did perform an evaluation, though the difference between these is not as substantial.

\section{Discussion}

The purpose of design research has been defined as both understanding and supporting design (Blessing \& Chakrabarti, 2009). The majority of research presented at NordDesign 2018 focused on supporting design, and more research focused on the development of new support than the application or evaluation of existing support. Based on the review of papers from NordDesign 2018, we discuss how design support was evaluated in practice and present suggestions to improve evaluation practices in the future.

\subsection{Evaluation of Design Support at NordDesign 2018}

\subsubsection{The High Focus on (New) Design Support}

It is fair to say that design support was a major focus at NordDesign 2018, as it was a main topic in $65 \%$ of papers. In contrast, only $9 \%$ of papers focused on describing industry practices and design behaviour in general without focussing on one particular type of support. However, if the purpose of design research is both to understand design and to support it, the results suggest that there might be a skewed balance in focus towards the development of design support over the development of knowledge about design.

In addition to the focus on design support, a higher amount of papers introduced new design support (64\%) than investigated existing support (39\%). In other words, more research effort was put into introducing new support than developing, validating and implementing support that already exist. Cantamessa (2001) found that 46\% of research at ICED 97 and 99 developed new methods and tools. At NordDesign $201842 \%$ of all papers introduced new design support. 
Thus, the same dominant focus on new design support is found at both design conferences, despite them taking place approximately 20 years apart.

The amount of design research has grown, making it is difficult to gain an overview of existing research and as a community we do not sufficiently reference the work of others (Blessing \& Chakrabarti, 2009). This increases the risk of re-developing something that already exists, instead of building on and furthering the existing knowledge. In other research fields, it is common to replicate the studies of others, but not in design research (Cash, 2018). Perhaps there is a feeling among design researchers that it is not enough to test an existing method or perform research simply to understand design, but that the understanding must be directly transferred into new support to become valuable. If so, this can be problematic as continuous work and development is required for support to be implemented and create value in industry. Perhaps some of the research effort spend on developing new support, should be spend on further evolving and implementing existing support.

\subsubsection{The Lack of (Rigorous) Evaluation}

Of the 41 papers that introduced new design support, $44 \%$ was evaluated in the papers, meaning that $56 \%$ of the papers simply introduced new support without any validation, evaluation or implementation. Literature states that evaluation is important for the success of support and more papers should attempt to incorporate validation or evaluation efforts. Many of the papers that introduced new support used words such as "first approaches", "a concept for a method" or "first version" which implies that this was the initial work and the authors did not consider it to be ready for evaluation. However, if all conferences have the same focus of $64 \%$ new support and $39 \%$ existing support, much of the introduced research will not be evaluated further.

While $44 \%$ of papers that introduced new support also evaluated the support, many of these evaluations are preliminary and limited. Half of evaluations were carried out by the authors themselves, meaning that only $22 \%$ of all new support papers included feedback from intended users. Further, the objectives for $67 \%$ of new support evaluations were either identifying general learnings or applying the developed support on a selected case. Thus, these papers mostly did not present a clear focus or goal for the evaluations other than 'learning' and they rarely presented clear results or conclusions from their work. Despite this, they concluded that their support had been validated, verified, or evaluated. One could consider whether these are demonstrations rather than evaluations. For instance, one paper stated; "Initial work on conceptualizing, developing, and testing such an environment is done through a pilot study based on two industrial use cases.", but contained no description of what was tested, how it was tested, and what conclusions were made. If the clear presentation of results from the evaluation had been a criterion for counting support as evaluated in this research, the number of papers that contain evaluations would be substantially lower.

In contrast, the evaluations of existing support were found to be more rigorous than the evaluations of new support on a number of parameters. More papers on existing research used evaluations by intended users, used quantitative measures in the evaluations, made comparisons between design support, and experimental studies were only carried out for existing support.

\subsubsection{Relative Impact of Design Support Papers}

If we alone consider the relative impact of design research from NordDesign 2018 as a measure for quality, we can disregard most of the previous discussion. Comparing the number of citations (excluding self-citations), papers on design support were cited seven times more that 
papers that did not focus on design support and papers that presented new design support were cited twice as much as papers on existing support. Furthermore, papers that did not perform any evaluations were cited a little more than papers that did an internal evaluation or evaluated with external users. This comparison implies that the research of most relevance to the design community are papers that present new design support, without evaluation. We do not believe this can be concluded, but think that the impact of different types of design research with different levels of rigour should be investigated further in the future.

\subsection{Implications on Future Evaluation Practices}

This paper illustrates the current evaluation practices in a section of published design research, which naturally leads to a discussion about implications for future practices. Based on the results in this paper, we present a list of suggested improvements of evaluations practices that have already been suggested in the existing literature and confirmed through this study:

- Greater balance between research that understands design and research that supports it. Greater focus and acceptance on design aiming at building theories for the understanding of design that is not necessarily directly applied in design support is needed.

- Greater balance between research on existing support and the creation of new support. If there is a need for design support, this must be tested, adjusted, related to other support, disseminated, and implemented to actually support practitioners.

- Increased rigour in evaluations. Rigour is needed in design research to increase relevance and impact (Cash, 2018). If a paper states that an evaluation was done, it should be easy to identify the evaluation in the paper and it should present results and conclusions clearly.

- Further research in the development and evaluation of successful design support. When developing new design support, a rigorous research methodology should be followed (Jagtap et al., 2014), but a systematic design methodology that provides details on the development of successful design support is missing (López-Mesa \& Bylund, 2011). Much literature exist on the topic of design support, but low efforts have gone into synthesizing these (Jagtap et al., 2014).

- Need for usability in design support. Factors such as user-friendliness and usefulness affect the adoption of new product development support (Thia et al., 2005). Just because a design support works and is theoretically able to create value in a design process, it does not mean that it will. Evaluation of design support should not only consider whether design support does what it attempts to do, but also that it is understandable by its intended users, that they perceive its value and can apply the support in their context.

- Reconsideration of measures of quality in design research. Is too much emphasis put on 'originality' or 'innovativeness' when research is evaluated?

\subsection{Contribution and Limitations}

This paper provides quantitative insights on the current evaluation practices from a section of the design research community. It contributes with an updated status of research within design support and make suggestions for the future development of evaluation practices. However, some limitations exit with regard to the reviewing process applied in the paper. Most of the papers in this review have not been read in their full length, but only the parts of the papers needed for the coding. If relevant information was placed in unconventional places, it may not have been included. Most importantly, results are based on a single conference, and therefore the results cannot be generalised to other conferences or the design research community as a whole. Future research should expand the scope of this or similar studies to include papers from other design conferences or journals over a longer period of time. 


\subsection{Conclusion}

Design support can benefit practitioners, but it must be evaluated. This paper investigated how design support was evaluated in the papers presented at the design conference NordDesign in 2018. Design support was a popular research area at the conference with $65 \%$ of papers focussing on this topic. More focus was put on new support (64\%) than existing support (39\%). However, only $44 \%$ of papers that presented new support did any evaluation and only half of them evaluated with intended users. The results indicate a skewed balance between research that understands design and research that supports it, as well as a lack of evaluation and rigour in evaluation of new design support. Future design research should provide more guidance on the development and evaluation of usable and successful design support.

\section{References}

Blessing, L. T. M., \& Chakrabarti, A. (2009). DRM, a design research methodology. Springer.

Booker, J. (2012). A survey-based methodology for prioritising the industrial implementation qualities of design tools. Journal of Engineering Design, 23(7), 507-525. https://doi.org/10.1080/09544828.2011.624986

Cantamessa, M. (2001). Design Research in Perspective-A Meta-Research on ICED 97 and ICED 99. ICED 01. ICED, Glasgow.

Cash, P. J. (2018). Developing theory-driven design research. Design Studies, 56, 84-119. https://doi.org/10.1016/j.destud.2018.03.002

Ioannidis, J. P. A. (2018). Meta-research: Why research on research matters. PLOS Biology, 16(3), e2005468. https://doi.org/10.1371/journal.pbio.2005468

Jagtap, S., Warell, A., Hiort, V., Motte, D., \& Larsson, A. (2014). Design Methods and Factors Influencing Their Uptake in Product Development Companies: A Review. 10.

Jensen, L. S. (2018). Design by Prototyping in Hardware Start-ups [Ph.D. Thesis]. Technical University of Denmark.

Kouprie, M. (2009). A framework for empathy in design: Stepping into and out of the user's life. Journal of Engineering Design, 20(5), 437-448. https://doi.org/10.1080/09544820902875033

López-Mesa, B., \& Bylund, N. (2011). A study of the use of concept selection methods from inside a company. Research in Engineering Design, 22(1), 7-27. https://doi.org/10.1007/s00163-010-0093-2

Nielsen, J. (2017, December 24). A 100-Year View of User Experience (by Jakob Nielsen). Nielsen Norman Group. https://www.nngroup.com/articles/100-years-ux/

Norddesign 2018. (n.d.). Retrieved 8 January 2020, from http://norddesign2018.org

The Design Society. (2018). DS 91: Proceedings of NordDesign 2018, Linköping, Sweden, 14th - 17th August 2018. The Design Society - a Worldwide Community.

Thia, C. W., Chai, K., Bauly, J., \& Xin, Y. (2005). An exploratory study of the use of quality tools and techniques in product development. The TQM Magazine, 17(5), 406-424. https://doi.org/10.1108/09544780510615924

Yeh, T.-M., Pai, F.-Y., \& Yang, C.-C. (2010). Performance improvement in new product development with effective tools and techniques adoption for high-tech industries. Quality \& Quantity, 44(1), 131-152. https://doi.org/10.1007/s11135-008-9186-7 